\title{
Concurrent validity of skin carotenoid status as a concentration biomarker of vegetable and fruit intake compared to multiple 24-h recalls and plasma carotenoid concentrations across one year: a cohort study
}

Lisa Jahns ${ }^{1 *}$ D, LuAnn K. Johnson ${ }^{1}$, Zach Conrad ${ }^{1,2}$, Michael Bukowski ${ }^{1}$, Susan K. Raatz ${ }^{1,3}$, Stephanie Jilcott Pitts ${ }^{4}$, Youfa Wang ${ }^{5}$, Igor V. Ermakov ${ }^{6}$ and Werner Gellermann ${ }^{6}$

\begin{abstract}
Background: Biological markers of vegetable and fruit (VF) intake are needed both for nutrition surveillance and for the evaluation of nutrition interventions. Optically assessed skin carotenoid status (SCS) has been proposed as a marker of intake but there are few published validity studies to date. Therefore, the objective of the study was to examine the concurrent validity of multiple methods of assessing VF intake cross-sectionally and seasonally over one year and to discuss the relative merits and limitations of each method.

Methods: Fifty-two 40-60 y old women completed a 1-year longitudinal study that included 1) SCS assessment using resonance Raman spectroscopy (RRS) and using pressure-mediated reflection spectroscopy (RS) at 12 timepoints, 2) thirty-six 24-h recalls using the Automated Self-Administered 24-Hour Dietary Assessment Tool (ASA24; total 1866 recalls), and 3) plasma carotenoid concentrations measured every 3 months. Pearson correlation coefficients and mixed linear models were used to estimate pairwise correlations between RRS, RS, ASA24, and plasma carotenoids.
\end{abstract}

Results: RS and RRS were strongly correlated at baseline and over the year ( $r=0.86$ and 0.76 ; respectively, $P<$ $0.001)$. RS was strongly correlated with plasma carotenoids at baseline $(r=0.70)$ and moderately across the year $(r=$ $0.65)$, as was RRS ( $r=0.77$ and 0.69 , respectively, all $P<0.001)$. At baseline, self-reported VF was weakly correlated with RRS $(r=0.33 ; P=0.016)$, but not with RS or plasma carotenoids. Across the year, self-reported VF intake was weakly correlated with both RS $(r=0.37 ; P=0.008)$, RRS $(r=0.37 ; P=0.007)$, and with plasma carotenoids $(r=0.36$; $P<0.008)$.

Conclusions: SCS as measured by RS and RRS is moderately to strongly correlated with plasma carotenoid concentrations both cross-sectionally and longitudinally, indicating that it can be a powerful tool to assess carotenoid-rich VF intake in populations.

(Continued on next page)

\footnotetext{
* Correspondence: lisa.jahns@usda.gov

${ }^{1}$ United States Department of Agriculture, Agricultural Research Service, Grand Forks Human Nutrition Research Center, 2420 2nd Avenue North, Grand Forks, ND 58203, USA

Full list of author information is available at the end of the article
}

(c) The Author(s). 2019 Open Access This article is distributed under the terms of the Creative Commons Attribution 4.0 International License (http://creativecommons.org/licenses/by/4.0/), which permits unrestricted use, distribution, and reproduction in any medium, provided you give appropriate credit to the original author(s) and the source, provide a link to the Creative Commons license, and indicate if changes were made. The Creative Commons Public Domain Dedication waiver (http://creativecommons.org/publicdomain/zero/1.0/) applies to the data made available in this article, unless otherwise stated. 
(Continued from previous page)

Clinical trial registry: This trial was registered at ClinicalTrials.gov as NCT01674296.

Keywords: Resonance Raman spectroscopy, Reflection spectroscopy, Skin carotenoids, Biomarkers, Vegetables, Fruits, ASA24 Dietary Assessment Tool, Dietary intake, Women, Cohort study

\section{Background}

Adequate vegetable and fruit (VF) intake is associated with reduced risk of several chronic diseases [1]. Yet in many populations intake is either declining [2] or remaining stable at insufficient amounts [3]. Despite large investments in initiatives like the 5-A-Day program $[4,5]$, increasing VF intake still confounds clinicians and public health nutrition professionals. Accurately measuring VF intake is crucial for population surveillance and for evaluating the efficacy of interventions, but a key dilemma in this pursuit has been inherent bias and error in selfreported measurement tools such as food frequency questionnaires, food records, and 24-h recalls [6].

There is a need for biological markers of dietary intake [7]. Ideally, a biomarker would pass through the body unaffected and be recovered in its entirety. To date, no such recovery biomarker exists for VF, but concentration biomarkers have been identified. Concentration biomarkers reflect the status of the marker of interest in the body and therefore are affected by individual differences in absorption, transport, and metabolism [7]. The Institute of Medicine called blood carotenoid concentrations the best biomarker of VF intake [8]; however, collecting and analyzing blood carotenoids is prohibitive for many studies. Optically-assessed skin carotenoid status (SCS) has been proposed as a concentration biomarker of carotenoid intake for monitoring VF intake and for assessing change in VF intake as a result of interventions [9]. SCS has favorably compared to carotenoid content of biopsied skin $[10,11]$ and to blood carotenoid concentrations $[10,12]$. SCS was also responsive to changes in VF intake in a controlled feeding study [13]. Seasonal differences in sun exposure and VF intake are purported to affect SCS, but the literature is mixed [13, 14].

There are two methodologies for measuring SCS; resonance Raman spectroscopy (RRS) $[15,16]$ and reflection spectroscopy (RS) $[9,16,17]$. RRS has been used in most of the existing studies and found to be representative of longer-term intake than blood carotenoid concentrations, perhaps by $1-2$ weeks $[10,15,18,19]$. RS represents an improvement over RRS as it corrects for effects of residual chromophores like blood and melanin in the skin [16]. RS was validated against plasma carotenoids in a racially/ethnically diverse sample [20] and is correlated with RRS [16]; yet, to the best of our knowledge, no studies have cross-validated multiple objective measures of VF intake (RRS, RS, and plasma carotenoid concentrations) and subjective measures of VF intake (self-report). This represents an important research gap that can be used to improve assessment of VF intake and change data.

Therefore, the purpose of this study was to examine the concurrent validity of multiple methods of assessing VF intake. We estimated baseline and yearlong pairwise correlations between 4 methods of assessing VF intake: 1) plasma carotenoid concentration, 2) multiple 24-h recalls, 3) RRS, and 4) RS. A secondary aim of the study was to examine potential seasonal differences in the measurements obtained using each method.

\section{Subjects and methods \\ Study design and subjects}

The present study reports a secondary outcome using data from an existing study and should be considered exploratory. The study sample consisted of 52 mid-life women who completed the Life in all Seasons (LENAS) study. LENAS utilized a closed cohort design and was conducted in two groups between July 2012 and July 2014. The study was designed to measure seasonal changes in diet, physical activity, and body composition over a 1-year period. Details have been reported elsewhere [21, 22]. Seventy-three women attended informational meetings and 61 signed informed consents. Fifty-four women began the study and two dropped out due to time constraints. Briefly, over a 1year period, women completed 24-h diet recalls (24-HR) every 10 days at home, had their SCS measured 12 times (monthly), and had plasma collected 4 times (once every three months at the midpoint of each season). Individuals were recruited by advertisements posted at the University of North Dakota and the surrounding area. Inclusion criteria were ages $40-60$ years, body mass index (BMI; kg/ $\mathrm{m}^{2}$ ) between 18 and 35, access to high-speed internet, and weight being stable for the previous 6 months (no more than $\pm 4.5 \mathrm{~kg}$ ). The majority (96\%) of the participants were non-Hispanic white, with a mean age of $49.4 \pm 0.8$ years and mean BMI of $26.5 \pm 0.6$; $33 \%$ were affected by overweight and $23 \%$ by obesity [21]. None of the participants reported current smoking. The study protocol was approved by the Institutional Review Board of the University of North Dakota and all participants provided informed written consent.

\section{Skin carotenoid measurements}

Skin carotenoid measurements were taken by both RRS and RS twelve times over the year, approximately one 
month apart. The two devices used were built by the authors (IVE and WG) for use with nutrition studies. RRS uses a $488 \mathrm{~nm}$ solid-state laser for blue light excitation of the tissue carotenoids. The laser light is directed onto the skin via optical fiber delivery and a collection module is placed in contact with the palm of the hand. Light backscattered from the skin is routed via a second fiber to a spectrograph interfaced with a cooled charge coupled device detector array. The recorded spectrum is analyzed for resonance Raman response of the skin carotenoids at their carbon double bond $(\mathrm{C}=\mathrm{C})$ frequency at $1525 \mathrm{~cm}^{-1}$, which appears at around $527 \mathrm{~nm}$ in the Raman spectrum. Since almost all carotenoid subspecies contribute almost equally to this frequency (excluding phytoene and phytofluene) [11], RRS intensity can be used as a measure for total carotenoid content. The instrument sensitivity was checked daily against a calibration standard (sodium nitrate), and individual skin carotenoid RRS intensities were calibrationadjusted. The intraindividual variability between the 3 scans is $5 \%$ on this instrument.

Instead of a laser, the RS methodology uses a broadband white light to measure skin carotenoids and other chromophores like melanin and hemoglobin directly through their respective absorptions in the $400-750 \mathrm{~nm}$ spectral window [17]. The reflected light is routed to a spectrograph coupled with a room-temperature detector array. The subject applies gentle pressure against a lens to temporarily squeeze blood out of the tissue that reduces potentially confounding effects of chromophores such as hemoglobin. The data processing algorithm also adjusts for the potentially confounding effects of melanin and tissue scattering. In this study, a prototype instrument was used that took measurements in the thumb; current commercially available technology takes measurements in the fingers. The intra-individual variability of the prototype instrument varies between 0.5 and $14 \%$, depending on the individual. Each individual's palm (RRS) and thumb (RS), were scanned 3 times and the average value used in the analysis.

\section{Dietary intake of vegetables, fruits, and carotenoids}

Approximately every 10 days, participants completed an online dietary recall using the US National Cancer Institute $(\mathrm{NCI})$ 's Automated Self-Administered 24-h Dietary Assessment Tool (ASA24-2011) [23, 24]. ASA24 prompts individuals to record everything consumed in the previous $24 \mathrm{~h}$ from midnight to midnight using detailed probes and has been validated against interviewer-administered 24-h recalls and actual intakes $[25,26]$. Provided reports included servings of VF derived from the USDA Food and Nutrient Database for Dietary Studies 4.0 [27] and the USDA MyPyramid Equivalents Database 2.0 [28], and dietary carotenoids (mg) estimated using data from the USDA Standard Reference 22 [29] database. Participants completed a total of 1866 diet recalls with a 92\% response rate for all 36 recalls (range 33-37); no recalls were excluded as day-to-day variation in intake was expected over the course of the year. Participants were not provided feedback or results from their recalls.

\section{Blood sample and carotenoid analysis}

At the midpoint of each meteorological season [summer (July), fall (October), winter (January), and spring (April)], fasting blood samples were taken by a trained phlebotomist, centrifuged and immediately stored at $-80^{\circ} \mathrm{C}$. Human plasma carotenoid $(\alpha-, \beta$ - carotenes, $\beta$-cryptoxanthin, lycopene and lutein/zeaxanthin) analysis was performed using Bukowski, et al's "dilute-and-shoot" [30] method by LC-MS/MS (LCMS-8050, Shimadzu). Under reduced lighting a $10 \mu \mathrm{L}$ aliquot of human plasma was combined with $990 \mu \mathrm{L}$ of methanol containing internal standard and was centrifuged to remove protein. The supernatant was transferred to 1-mL amber glass vial for analysis. A volume of $25 \mu \mathrm{L}$ was injected onto a C-30 column (YMC Carotenoid, $10 \times 2 \mathrm{~mm}, 3 \mu \mathrm{m}$ particle size) with an initial 9:1 methanol water mobile phase, which concentrated analytes on the front of the column, allowing for the removal of phospholipid interferences that suppress ionization. After the washout period, the mobile phase transitioned over two minutes to 70:20:10 acetonitrile: methylene chloride: methanol $(20 \mathrm{mM}$ ammonium acetate, $0.3 \%$ acetic acid). Analytes were eluted over $35 \mathrm{~min}$ following the order observed by Melendez-Martinez [31] and were quantitated against the internal standard of tocol. This method was validated by analysis of all three levels of NIST SRM 968e. Measured values for all analytes were within the stated tolerance for this SRM.

As an additional validation step, a set of standard addition experiments were performed. Four aliquots of plasma were spiked with increasing levels of the analytes from a standard solution. The measured concentrations for these samples were plotted against the size of the spike added to the plasma and fit with a linear regression. The $y$-intercepts for these regressions agreed within $2-5 \%$ of the measured concentrations for the unspiked plasma sample. This indicated that there were no matrix effects or artifacts from sample preparation.

\section{Statistical analysis}

RRS, RS, and self-reported dietary VF and carotenoid values are presented as means \pm standard error of the mean (SEM). Plasma carotenoid values were skewed according to the Kolmogorov-Smirnov test, so values were log-transformed for analysis. Back-transformed means -1SEM, +1SEM are presented.

Effects of season were tested using mixed linear models, in which season was the fixed effect and participant was the random effect. For RRS, RS and self-reported dietary 
VF and carotenoid values, multiple measurements obtained for each participant during each season were averaged and used as the dependent variable in the model. If the overall model was significant, Tukey's contrasts were used to make pairwise comparisons among all seasons.

Pairwise correlations between baseline measures of carotenoid status and intake and VF intake obtained by the 4 methods (i.e. RRS, RS, plasma, and self-report) were estimated using Pearson correlations.

Finally, we examined the relationship of optically assessed SCS to self-reported dietary intake and to total plasma carotenoid concentrations across 1 year. To assess the correlation between plasma and skin carotenoids, we used the skin carotenoid measurements from the same day that blood was drawn (4 time points; once each season). For the correlation of plasma and dietary carotenoids, we used the closest dietary recall preceding the blood draw. To assess correlation between SCS and dietary carotenoids, we used the closest preceding dietary recall at each month (12 time points; once each month). Maximum likelihood estimation was used to calculate the overall correlation of each pair of variables of interest using all available measurements. The method used [32] provides estimates of both the withinindividual correlation and the between-individual correlation across the course of the study and correctly accounts for the multiple measurements on each subject. The relationship between RRS and RS was further investigated by fitting a mixed effects linear model (Fig. 1). In the model used, referred to as a random slopes model, the overall slope was modeled as a fixed effect while allowing for a random deviation from the overall slope for each individual. The correlation between observations arising from each individual was also accounted for in the model, and BMI was included as a covariate. All analyses were conducted using SAS version 9.4; (SAS Institute, Inc., Cary, North Carolina) and a $P$ value of $<0.05$ was considered significant. As adapted from Mukaka for studies related to medical research [33], the interpretation of the correlation coefficients was as follows: $0.00-0.49=$ weak, $0.50-0.69=$ moderate, and $0.70+=$ strong .

\section{Results}

\section{Seasonal differences in study variables}

There were no seasonal differences in RS intensities $(P=0.500)$; however, RRS scores were marginally lower in summer than in spring or fall $(P<0.001)$ (Table 1$)$. Total plasma carotenoid concentrations also differed marginally by season $(P=0.025)$, with the lowest occurring in summer and the highest occurring in spring. Neither self-reported VF $(P=0.441)$ nor self-reported carotenoid intake $(P=0.983)$ differed by season.

\section{Correlations between RS and RRS}

At baseline, RS and RRS were strongly correlated $(r=0.86$; $P<0.001)$. Figure 1 displays the relationship between RS

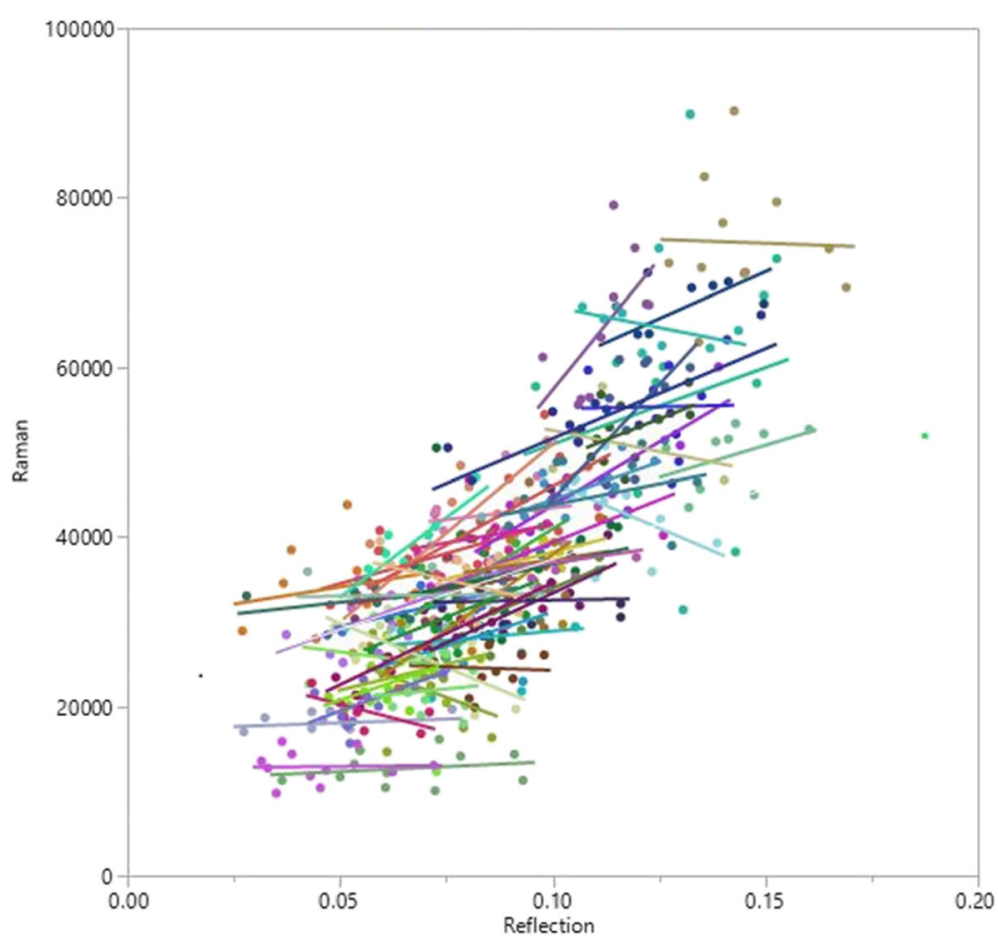

Fig. 1 RS compared with RRS intensities for 52 women over 12 time points. Colored lines represent the slope for each person over the year. Per maximum likelihood, the overall between-person correlation between the two skin carotenoid scores was $0.76(P<0.001)$ and the overall withinperson correlation coefficient was $0.30(P<0.03)$. RS, reflection spectroscopy; RRS, resonance Raman spectroscopy 
Table 1 Mean $( \pm$ SEM) values of study variables by season among US women $(N=52)$ living in North Dakota, USA

\begin{tabular}{|c|c|c|c|c|c|}
\hline & Spring & Summer & Fall & Winter & $P$-value \\
\hline & \multicolumn{5}{|l|}{ Mean \pm SEM } \\
\hline \multicolumn{6}{|l|}{ Skin carotenoid status } \\
\hline RRS intensities ${ }^{\mathrm{b}}$ & $38,238^{x} \pm 2617$ & $34,629^{y} \pm 1910$ & $37,044^{x} \pm 2043$ & $36,563^{x y} \pm 1818$ & $<0.001$ \\
\hline RS intensities ${ }^{\mathrm{b}}$ & $0.091 \pm 0.004$ & $0.087 \pm 0.004$ & $0.088 \pm 0.004$ & $0.088 \pm 0.004$ & 0.500 \\
\hline \multicolumn{6}{|l|}{ Dietary Intake } \\
\hline Vegetable and fruit (g/d) & $188 \pm 16$ & $220 \pm 16$ & $194 \pm 16$ & $187 \pm 18$ & 0.441 \\
\hline \multirow[t]{2}{*}{ Dietary carotenoids (mg/d) } & $12.1 \pm 0.76$ & $12.0 \pm 0.97$ & $11.9 \pm 0.72$ & $11.9 \pm 1.11$ & 0.983 \\
\hline & \multicolumn{5}{|c|}{ Geometric mean -1SEM, +1SEM } \\
\hline Total plasma carotenoids $(\mu \mathrm{M} / \mathrm{L})^{c}$ & $2.53 ; 2.36,2.71^{\times}$ & $2.26 ; 2.11,2.42^{y}$ & $2.46 ; 2.30,2.64^{x y}$ & $2.34 ; 2.18,2.51^{x y}$ & 0.025 \\
\hline
\end{tabular}

${ }^{a}$ Measured by the Automated Self-Administered 24-Hour (ASA24) Dietary Assessment Tool at 36 times over the year

${ }^{b}$ Measured at 12 times over the year

${ }^{c}$ Measured at 4 times over the year

-Analyzed carotenoids were $\alpha$ - and $\beta$-carotene, $\beta$-cryptoxanthin, lycopene, lutein and zeaxanthin.

$x, y$, Values between seasons with the same superscript letters are not significantly different $(P>0.05)$ by Tukey contrasts.

$\mathrm{RS}$, reflection spectroscopy.

RRS, resonance Raman spectroscopy.

and RRS over the year. Based on the mixed linear model fit of the data, the between-person correlation was strong $(r=0.76 ; P<0.001)$, but the overall within-person correlation was weak $(r=0.30 ; P=0.03)$. Each individual's slope is displayed and within-person correlations ranged from $r=-0.71$ to 0.87 ; median: $r=0.30$.

\section{Baseline and full-year pairwise correlations}

Baseline and between-individual correlations across the year are presented in Table 2. RS was strongly correlated with plasma carotenoids at baseline $(r=0.70 ; P<0.001)$, but moderately across the year $(r=0.65 ; P<0.001)$, as was RRS $(r=0.77$ and 0.69 , respectively; $P<0.001)$. At baseline, self-reported VF was weakly correlated with RRS $(r=0.33 ; P=0.016)$ but not with RS $(P=0.053)$ or plasma carotenoids $(P=0.050)$. Across the year, self- reported VF intake was weakly correlated with RS and RRS ( $r=0.37$ for both; $P<0.01$ ), and with plasma carotenoids $(r=0.36 ; P=0.008)$. Dietary carotenoids were not correlated with RS $(P=0.500)$, RRS $(P=0.057)$, or plasma $(P=0.089)$ at baseline, but were moderately correlated with VF intake $(r=0.56 ; P<0.001)$. Over the year, dietary carotenoids were weakly correlated with RRS $(r=0.29 ; P=0.034)$ and plasma carotenoids $(r=$ $0.34 ; P=0.15)$, and moderately correlated with VF intake $(r=0.51 ; P<0.001)$.

\section{Discussion}

This study demonstrated that SCS measured by RS is highly correlated with RRS and with plasma carotenoid concentrations and is weakly correlated with dietary intake of carotenoids or VF measured by self-report. If

Table 2 Correlation coefficients ${ }^{\mathrm{a}}$ and $95 \%$ confidence intervals of skin carotenoids, plasma carotenoids, and self-reported vegetable and fruit intake at baseline and across one year

\begin{tabular}{|c|c|c|c|c|c|c|}
\hline & \multicolumn{2}{|c|}{ Total plasma carotenoids $(\mu \mathrm{M} / \mathrm{L})^{\mathrm{d}}$} & \multicolumn{2}{|c|}{ VF (cup eq. $)^{b}$} & \multicolumn{2}{|c|}{ Dietary carotenoids $(\mathrm{mg} / \mathrm{d})^{\mathrm{b}}$} \\
\hline & Baseline & Year & Baseline & Year & Baseline & Year \\
\hline Reflection spectroscopy ${ }^{c}$ & $\begin{array}{l}0.70 * * * \\
(0.53,0.82)\end{array}$ & $\begin{array}{l}0.65^{* * *} \\
(0.46,0.79)\end{array}$ & $\begin{array}{l}0.27 \\
(0.00,0.51)\end{array}$ & $\begin{array}{l}0.37^{* *} \\
(0.10,0.58)\end{array}$ & $\begin{array}{l}0.10 \\
(-0.18,0.36)\end{array}$ & $\begin{array}{l}0.24 \\
(-0.03,0.48)\end{array}$ \\
\hline Resonance Raman spectroscopy ${ }^{c}$ & $\begin{array}{l}0.77^{* * *} \\
(0.63,0.86)\end{array}$ & $\begin{array}{l}0.69 * * * \\
(0.52,0.81)\end{array}$ & $\begin{array}{l}0.33^{*} \\
(0.06,0.55)\end{array}$ & $\begin{array}{l}0.37^{* *} \\
(0.11,0.59)\end{array}$ & $\begin{array}{l}0.27 \\
(0.00,0.51)\end{array}$ & $\begin{array}{l}0.29 * \\
(0.02,0.52)\end{array}$ \\
\hline Total plasma carotenoids $(\mu \mathrm{M} / \mathrm{L})^{\mathrm{d}}$ & & & $\begin{array}{l}0.27 \\
(0.00,0.51)\end{array}$ & $\begin{array}{l}0.36^{* *} \\
(0.10,0.58)\end{array}$ & $\begin{array}{l}0.24 \\
(-0.03,0.48)\end{array}$ & $\begin{array}{l}0.33^{*} \\
(0.06,0.55)\end{array}$ \\
\hline VF (cup eq. $)^{b}$ & & & & & $\begin{array}{l}0.56^{* * *} \\
(0.34,0.72)\end{array}$ & $\begin{array}{l}0.51^{* * *} \\
(0.27,0.69)\end{array}$ \\
\hline
\end{tabular}

apairwise correlations at baseline were estimated using Pearson coefficients and full-year between-individual correlations were estimated using a mixed model

${ }^{\mathrm{b}}$ Measured by the Automated Self-Administered 24-Hour (ASA24) Dietary Assessment Tool at 36 times over the year

${ }^{\mathrm{C}}$ Measured at 12 times over the year

${ }^{\mathrm{d}}$ Measured at 4 times over the year

Analyzed carotenoids were $\alpha$ - and $\beta$-carotene, $\beta$-cryptoxanthin, lycopene, lutein and zeaxanthin

*Significant at $P<0.05$

**Significant at $P<0.01$

***Significant at $P<0.001$ 
plasma carotenoid concentrations are considered the reference biomarker, then our results indicate that SCS may be considered a superior method to self-report for assessing VF intake. However, multiple assessment methods may be needed to gain a more complete assessment of VF intake. Self-report methods can be expensive if interviewer-assisted, and are potentially subject to participant bias such as social desirability [34], whereas SCS cannot detect intake of non-carotenoid-rich VF, such as potatoes or mushrooms. Self-report, by either 24-HR or food frequency questionnaire (FFQ), is the only way to determine overall dietary patterns. Similar to blood carotenoids, SCS is affected by factors that influence the absorption, transport, and metabolism of carotenoids [35], such as the food matrix [36] or genetics [37], and may be affected by environmental factors, such as smoking, sun exposure, or adiposity, therefore it is (thus far) not possible to link a given SCS score with a specific intake of VF. Regardless, SCS is another tool that public health researchers and clinicians may use for surveillance and assessment of the effectiveness of interventions. For example, SCS is being used to determine the effectiveness of a cost-offset Community Supported Agriculture (CSA) project among low-income children and their caregivers [38] and to determine the effectiveness of a healthy corner store initiative in North Carolina [20,39]. The present study is especially pertinent as it is the first longitudinal study to assess the relative validity of RS, which is more widely available compared to the RRS technology.

Many factors may have influenced our observed results. Scarmo and colleagues compared SCS (measured by RRS) values over a 6-month period and found good agreement over time, although they also found that RRS scores were lower in summer, as we found [14]. We did not find strong correlations between SCS and dietary carotenoids in the current study. However, Mayne et al., compared SCS (measured by RRS) to dietary carotenoids measured by a 2month FFQ (representing "usual" intake) and found a correlation of 0.57 [10]. To put this in perspective, many FFQs are validated compared to blood carotenoid concentrations, with correlations $\sim 0.2-0.5$ [40-42]. As a year's worth of 24-HR may also be considered to approximate "usual" intake, we found similar correlations with VF intake of $r=0.37$ using either SCS method for between-person correlations; generally the only coefficient measured in validation studies. However, within an individual, we found very poor correlations with plasma and dietary intakes for both SCS methods (data not shown), suggesting that SCS is a better indicator of group intakes than of individual intakes. This may be reflective of a number of factors: 1) As there was only marginal variation between seasons in either self-reported VF or dietary carotenoids, these low levels of variability in intake of VF and dietary carotenoids may be at least partially responsible for the low observed correlations; 2) vegetables are often consumed in mixed dishes, which are notoriously difficult to assess and rely upon the best judgement of the respondent to identify a food code similar to what they consumed, which is linked to a recipe similar to that consumed by the respondent, which is then linked to nutrient databases that have their own set of errors. Factors other than vegetable and fruit intake affect blood carotenoid concentrations, and therefore may be expected to impact observed SCS as well. Animal foods, such as eggs (a rich source of lutein), shellfish and salmon contain carotenoids. Genetics is probably the most influential; single nucleotide polymorphisms in the $\beta, \beta$ carotene $15,15^{\prime}$-oxygenase 1 [43, 44] gene, as well as others [45-47], are beginning to be described as affecting blood carotenoid concentrations. Other factors may also play a role, such as smoking, adiposity, sun exposure and oxidative stress exposure, such as chronic illness [15]. Individuals with metabolic syndrome have lower levels of SCS than healthy individuals [48]. In addition, carotenoids are sequestered into other body tissues, such as adipose [49], eye [50], bone [51], and brain [52], leading to competition for skin deposition with resultant variability in tissue levels of carotenoids [5355]. The kinetics of carotenoids depositing into skin are still not well-defined, and it is unknown how SCS responds to different doses of VF.

SCS as a biomarker of VF intake has been proposed and several validation studies have been published [9]. However, this is the first study to compare RS to RRS, and the first to compare SCS to 24-HR data. Specifically, strengths of this study include the full year longitudinal nature of the data as it allowed us to examine correlations both between and within individuals over time, as well as cross-sectionally at baseline. The use of the ASA24 can also be considered a strength as it collects detailed dietary information. This study also has several limitations to consider. The sample is small, homogeneous, and not generalizable to the larger US population. The women who participated were also overweight; only $23 \%$ had obesity. Thus, our results may differ in lean populations and people with obesity. SCS, in addition to the caveats listed above, is limited in that it only responds to carotenoid-rich foods. However, it is an objective measure, and current dietary guidance specifically recommends intake of dark green and orange and red vegetables, which are rich in carotenoids [56]. SCS was poorly correlated with baseline self-reported VF intake, which is not surprising considering that 24-HRs estimate only short-term intake, while SCS may be expected to represent longer-term tissue stores. The RS device used in this study was a prototype, and the commerciallyavailable RS device may be more sensitive.

\section{Conclusions}

In conclusion, we found that SCS is strongly correlated to plasma carotenoids, but weakly to self-reported VF 
intake. This begs the question, which method do we choose to evaluate our interventions? In this long-term study, we have shown that plasma carotenoid concentrations, the gold standard for VF intake, are strongly correlated with RS and RRS but only weakly correlated with self-reported dietary intake of VF. SCS, particularly as measured by RS, is rapid, non-invasive and does not require specialized training or data processing compared to blood carotenoid analysis. Our results indicate that SCS assessed via RRS and RS is more strongly associated with plasma carotenoids than is self-reported VF or carotenoid intake. At this point, there are a variety of methods to assess changes in VF intake, and we cautiously suggest that SCS can be another tool that researchers and clinicians may utilize when attempting to change dietary behavior or during population-level monitoring and surveillance.

\section{Abbreviations}

ASA24: Automated Self-Administered 24-Hour Dietary Assessment Tool; RRS: resonance Raman spectroscopy; RS: reflection spectroscopy; SCS: skin carotenoid status; VF: vegetables and fruits

\section{Acknowledgements}

Not applicable.

\section{Authors' contributions}

$L J$ designed and conducted research; IE and WG provided essental materials, MB analyzed data, LKJ performed statistical analysis; all authors interpreted results and wrote the paper; $\sqcup$ had primary responsibility for final content. All authors read and approved the final manuscript.

\section{Funding}

United States Department of Agriculture, Agricultural Research Service 306251000-051-00D.

\section{Availability of data and materials}

Data described in the manuscript, code book, and analytic code will be made available upon request pending approval and signed agreements.

\section{Ethics approval and consent to participate}

The study protocol was approved by the Institutional Review Board of the University of North Dakota and all participants provided informed written consent.

\section{Consent for publication}

Not applicable.

\section{Competing interests}

WG and IE hold patents on the reflection technology and are with Longevity Link Corporation, the maker of the instrumentation used in this study The other authors declare that they have no competing interests.

\section{Author details}

${ }^{1}$ United States Department of Agriculture, Agricultural Research Service, Grand Forks Human Nutrition Research Center, 2420 2nd Avenue North, Grand Forks, ND 58203, USA. ²Department of Health Sciences, William \& Mary, 251 Ukrop Way, Williamsburg, VA 23185, USA. ${ }^{3}$ Department of Food Science and Nutrition, 225 Food Science and Nutrition, 1334 Eckles Ave, St. Paul, MN 55108, USA. ${ }^{4}$ Department of Public Health, Brody School of Medicine, East Carolina University, 115 Heart Drive MS 660, Greenville, NC 27834, USA. ${ }^{5}$ Department of Nutrition and Health Sciences, College of Health, Ball State University, Muncie, IN 47306, USA. 'ongevity Link Corporation, University of Utah Research Park, 391 Chipeta Way Suite E, Salt Lake City, UT 84108, USA.
Received: 6 August 2019 Accepted: 30 October 2019

Published online: 21 November 2019

\section{References}

1. Aune D, Giovannucci EL, Boffetta P, Fadnes LT, Keum N, Norat T, et al. Fruit and vegetable intake and the risk of cardiovascular disease, total cancer and all-cause mortality-a systematic review and dose-response meta-analysis of prospective studies. Int J Epidemiol. 2017;46:1029-56.

2. Abe SK, Stickley A, Roberts B, Richardson E, Abbott P, Rotman D, et al. Changing patterns of fruit and vegetable intake in countries of the former Soviet Union. Public Health Nutr. 2013:16:1924-32.

3. Rehm CD, Peñalvo JL, Afshin A, Mozaffarian D. Dietary intake among us adults, 1999-2012. JAMA. 2016;315:2542-53.

4. Capacci S, Mazzocchi M. Five-a-day, a price to pay: an evaluation of the UK program impact accounting for market forces. J Health Econ. 2011;30:87-98.

5. Pomerleau J, Lock K, Knai C, McKee M. Interventions designed to increase adult fruit and vegetable intake can be effective: a systematic review of the literature. J Nutr. 2005;135:2486-95.

6. Subar AF, Freedman LS, Tooze JA, Kirkpatrick SI, Boushey C, Neuhouser ML, et al. Addressing current criticism regarding the value of self-report dietary data. J Nutr. 2015;145:2639-45

7. Jenab M, Slimani N, Bictash M, Ferrari P, Bingham SA. Biomarkers in nutritional epidemiology: applications, needs and new horizons. Hum Genet. 2009;125:507-25.

8. Institute of Medicine, National Academy of Sciences, Food and Nutrition Board, Panel on Dietary Antioxidants and Related Compounds. Dietary Reference Intakes for Vitamin C, Vitamin E, Selenium, and Carotenoids Washington: National Academy Press; 2000.

9. Ermakov IV, Ermakova M, Sharifzadeh M, Gorusupudi A, Farnsworth K, Bernstein PS, et al. Optical assessment of skin carotenoid status as a biomarker of vegetable and fruit intake. Arch Biochem Biophys. 2018;646:46-54.

10. Mayne ST, Cartmel B, Scarmo S, Lin H, Leffell DJ, Welch E, et al. Noninvasive assessment of dermal carotenoids as a biomarker of fruit and vegetable intake. Am J Clin Nutr. 2010;92:794-800.

11. Ermakov IV, Gellermann W. Validation model for Raman based skin carotenoid detection. Arch Biochem Biophys. 2010;504:40-9.

12. Nguyen LM, Scherr RE, Linnell JD, Ermakov IV, Gellermann W, Jahns L, et al. Evaluating the relationship between plasma and skin carotenoids and reported dietary intake in elementary school children to assess fruit and vegetable intake. Arch Biochem Biophys. 2015;572:73-80.

13. Jahns L, Johnson LK, Mayne ST, Cartmel B, Picklo MJ Sr, Ermakov IV, et al. Skin and plasma carotenoid response to a provided intervention diet high in vegetables and fruit: uptake and depletion kinetics. Am J Clin Nutr. 2014;100:930-7.

14. Scarmo S, Cartmel B, Lin H, Leffell DJ, Ermakov IV, Gellermann W, et al. Single V. multiple measures of skin carotenoids by resonance Raman spectroscopy as a biomarker of usual carotenoid status. Br J Nutr. 2013:911-7.

15. Mayne ST, Cartmel B, Scarmo S, Jahns L, Ermakov IV, Gellermann W. Resonance Raman spectroscopic evaluation of skin carotenoids as a biomarker of carotenoid status for human studies. Arch Biochem Biophys. 2013:539:163-70

16. Ermakov IV, Gellermann W. Optical detection methods for carotenoids in human skin. Arch Biochem Biophys. 2015:572:101-11.

17. Ermakov IV, Gellermann W. Dermal carotenoid measurements via pressure mediated reflection spectroscopy. J Biophotonics. 2012:5:559-70.

18. Scarmo S, Cartmel B, Lin H, Leffell DJ, Welch E, Bhosale P, et al. Significant correlations of dermal total carotenoids and dermal lycopene with their respective plasma levels in healthy adults. Arch Biochem Biophys. 2010;504:34-9.

19. Scarmo S, Henebery K, Peracchio H, Cartmel B, Lin H, Ermakov IV, et al. Skin carotenoid status measured by resonance Raman spectroscopy as a biomarker of fruit and vegetable intake in preschool children. Eur J Clin Nutr. 2012;66:555-60.

20. Jilcott Pitts SB, Jahns L, Wu Q, Moran NE, Bell RA, Truesdale KP, et al. A noninvasive assessment of skin carotenoid status through reflection spectroscopy is a feasible, reliable and potentially valid measure of fruit and vegetable consumption in a diverse community sample. Public Health Nutr. 2018:1664-70

21. Jahns L, Johnson LK, Scheett AJ, Stote KS, Raatz SK, Subar AF, et al. Measures of diet quality across calendar and winter holiday seasons among midlife women: a 1-year longitudinal study using the automated selfadministered 24-hour recall. J Acad Nutr Diet. 2016;116:1961-9. 
22. Jahns L, Conrad Z, Johnson LK, Scheett AJ, Stote KS, Raatz SK. Diet quality is lower and energy intake is higher on weekends compared with weekdays in midlife women: a 1-year cohort study. J Acad Nutr Diet. 2017;117:1961-9.

23. National Cancer Institute, Epidemiology and Genomics Research. ASA24 Automated Self-Administered 24-hour Recall. http://epi.grants.cancer.gov/ asa24/. Accessed 24 Oct 2019.

24. Subar AF, Kirkpatrick SI, Mittl B, Zimmerman TP, Thompson FE, Bingley C, et al. The automated self-administered 24-hour dietary recall (ASA24): a resource for researchers, clinicians, and educators from the National Cancer Institute. J Acad Nutr Diet. 2012;112:1134-7.

25. Thompson FE, Dixit-Joshi S, Potischman N, Dodd KW, Kirkpatrick SI, Kushi $\mathrm{LH}$, et al. Comparison of interviewer-administered and automated selfadministered 24-hour dietary recalls in 3 diverse integrated health systems. Am J Epidemiol. 2015;181:970-8.

26. Kirkpatrick SI, Subar AF, Douglass D, Zimmerman TP, Thompson FE, Kahle $L L$, et al. Performance of the automated self-administered 24-hour recall relative to a measure of true intakes and to an interviewer-administered 24h recall. Am J Clin Nutr. 2014;100:233-40.

27. USDA. Food and nutrient database for dietary studies, 4.1. Beltsville (MD): USDA, Agricultural Research Service, Food Surveys Research Group. 2010.

28. Bowman SA, Friday JE, Moshfegh A. MyPyramid equivalents database, 2.0 for USDA survey foods, 2003-2004.Beltsville: Beltsville Human Nutrition Research Center, Agricultural Research Service, U.S. Department of Agriculture; 2008.

29. US Department of Agriculture, Agricultural Research Service, Nutrient Data Laboratory. USDA National Nutrient Database for Standard Reference, Release 22. http://www.ars.usda.gov/ba/bhnrc/ndl. Accessed 24 October, 2019.

30. Bukowski MR, Voeller K, Jahns L. Simple and sensitive dilute-and-shoot analysis of carotenoids in human plasma. J Chromatogr B Analyt Technol Biomed Life Sci. 2018;1095:32-8.

31. Melendez-Martinez AJ, Stinco CM, Liu C, Wang XD. A simple HPLC method for the comprehensive analysis of cis/trans (Z/E) geometrical isomers of carotenoids for nutritional studies. Food Chem. 2013;138:1341-50.

32. Hamlett AC, Ryan L, Serrano-Trespalacios P, Wolfinger R. Mixed models for assessing correlation in the presence of replication. J Air \& Waste Manage Assoc. 2003:442-50.

33. Mukaka MM. Statistics corner: a guide to appropriate use of correlation coefficient in medical research. Malawi Med J. 2012;24:69-71.

34. Dietary Assessment Primer. National Institutes of Health, National Cancer Institute. http://dietassessmentprimer.cancer.gov/. Accessed 24 October, 2019.

35. Bohn T, Desmarchelier C, Dragsted LO, Nielsen CS, Stahl W, Rühl R, et al. Host-related factors explaining interindividual variability of carotenoid bioavailability and tissue concentrations in humans. Mol Nutr Food Res. 2017;61:1600685.

36. Rodriguez-Roque MJ, de Ancos B, Sanchez-Vega R, Sanchez-Moreno C, Cano MP, Elez-Martinez $P$, et al. Food matrix and processing influence on carotenoid bioaccessibility and lipophilic antioxidant activity of fruit juicebased beverages. Food Funct. 2016;7:380-9.

37. Borel P, Desmarchelier C. Genetic variations associated with vitamin a status and vitamin a bioavailability. Nutrients. 2017;9.

38. Seguin RA, Morgan EH, Hanson $\mathrm{KL}$, Ammerman AS, Jilcott Pitts $\mathrm{SB}$ Kolodinsky J, et al. Farm fresh foods for healthy kids (F3HK): an innovative community supported agriculture intervention to prevent childhood obesity in low-income families and strengthen local agricultural economies. BMC Public Health. 2017;17:306

39. Jilcott Pitts SB, Wu Q, Truesdale KP, Haynes-Maslow L, McGuirt JT, Ammerman A, et al. One-year follow-up examination of the impact of the North Carolina healthy food small retailer program on healthy food availability, purchases, and consumption. Int J Environ Res Public Health. 2018;15:2681.

40. Fraser GE, Jaceldo-Siegl K, Henning SM, Fan J, Knutsen SF, Haddad EH, et al. Biomarkers of dietary intake are correlated with corresponding measures from repeated dietary recalls and food-frequency questionnaires in the Adventist health Study-2. J Nutr. 2016;146:586-94.

41. Lassale C, Castetbon K, Laporte F, Deschamps V, Vernay M, Camilleri GM, et al. Correlations between fruit, vegetables, fish, vitamins, and fatty acids estimated by web-based nonconsecutive dietary records and respective biomarkers of nutritional status. J Acad Nutr Diet. 2016;116:427-38.

42. Carlsen MH, Karlsen A, Lillegaard ITL, Gran JM, Drevon CA, Blomhoff R, et al. Relative validity of fruit and vegetable intake estimated from an FFQ, using carotenoid and flavonoid biomarkers and the method of triads. Br J Nutr. 2011;105:1530-8
43. Leung WC, Hessel S, Meplan C, Flint J, Oberhauser V, Tourniaire F, et al. Two common single nucleotide polymorphisms in the gene encoding betacarotene 15,15'-monoxygenase alter beta-carotene metabolism in female volunteers. FASEB J. 2009:23:1041-53.

44. Lietz G, Oxley A, Leung W, Hesketh J. Single nucleotide polymorphisms upstream from the beta-carotene 15,15'-monoxygenase gene influence provitamin a conversion efficiency in female volunteers. J Nutr. 2012;142:161S-5S.

45. Borel P. Genetic variations involved in interindividual variability in carotenoid status. Mol Nutr Food Res. 2012;56:228-40.

46. Borel P, Lietz G, Goncalves A, Szabo de Edelenyi F, Lecompte S, Curtis P, et al. CD36 and SR-BI are involved in cellular uptake of provitamin A carotenoids by Caco- 2 and HEK cells, and some of their genetic variants are associated with plasma concentrations of these micronutrients in humans. Nutr. 2013;143:448-56.

47. Borel P, Moussa M, Reboul E, Lyan B, Defoort C, Vincent-Baudry S, et al. Human plasma levels of vitamin $\mathrm{E}$ and carotenoids are associated with genetic polymorphisms in genes involved in lipid metabolism. J Nutr. 2007:137:2653-9.

48. Holt EW, Wei EK, Bennett N, Zhang LM. Low skin carotenoid concentration measured by resonance Raman spectroscopy is associated with metabolic syndrome in adults. Nutr Res. 2014;34:821-6.

49. El-Sohemy A, Baylin A, Kabagambe E, Ascherio A, Spiegelman D, Campos H. Individual carotenoid concentrations in adipose tissue and plasma as biomarkers of dietary intake. Am J Clin Nutr. 2002;76:172-9.

50. Bernstein PS, Zhao DY, Sharifzadeh M, Ermakov IV, Gellermann W. Resonance Raman measurement of macular carotenoids in the living human eye. Arch Biochem Biophys. 2004;430:163-9.

51. Ermakov IV, Ermakova MR, Rosenberg TD, Gellermann W. Optical detection of carotenoid antioxidants in human bone and surrounding tissue. J Biomed Opt. 2013;18:117006.

52. Craft NE, Haitema TB, Garnett KM, Fitch KA, Dorey CK. Carotenoid, tocopherol, and retinol concentrations in elderly human brain. J Nutr Health Aging. 2004;8:156-62.

53. Parker RS. Carotenoid and tocopherol composition of human adipose tissue. Am J Clin Nutr. 1988;47:33-6.

54. Bernstein PS, Zhao DY, Wintch SW, Ermakov IV, McClane RW, Gellermann W. Resonance Raman measurement of macular carotenoids in normal subjects and in age-related macular degeneration patients. Ophthalmology. 2002;109:1780-7.

55. Arab L, Cambou MC, Craft N, Wesseling-Perry K, Jardack P, Ang A. Racial differences in correlations between reported dietary intakes of carotenoids and their concentration biomarkers. Am J Clin Nutr. 2011;93:1102-8.

56. US Department of Health and Human Services and US Department of Agriculture. 2015 - 2020 Dietary Guidelines for Americans. 8th Edition. 2015.

\section{Publisher's Note}

Springer Nature remains neutral with regard to jurisdictional claims in published maps and institutional affiliations.

Ready to submit your research? Choose BMC and benefit from:

- fast, convenient online submission

- thorough peer review by experienced researchers in your field

- rapid publication on acceptance

- support for research data, including large and complex data types

- gold Open Access which fosters wider collaboration and increased citations

- maximum visibility for your research: over $100 \mathrm{M}$ website views per year

At $\mathrm{BMC}$, research is always in progress.

Learn more biomedcentral.com/submission 